\section{'Gene hunting' in India}

SIR - Your recent News stories about 'gene-hunting' in India (see Nature 379, $381-382$; 1996) refer to a memorandum published by the Indian government's Ministry of Health and Family Welfare in 1992. This points out that the government does not object to biological samples being sent abroad for diagnostic purposes for studies that either cannot be done, or require research techniques that are not available, in India. Where the studies can be carried out in India, any proposal to send biological products abroad for such studies "should be sent to the DirectorGeneral, Indian Council of Medical Research, New Delhi, who will be the nodal point to clear all such proposals". The material sent abroad from the eye hospitals cited in the report was for collaborative research work, and therefore, despite the suggestion in your article, meets the requirements of regulations.

Furthermore, both the L. V. Prasad Eye Institute (LVPEI) in Hyderabad and the Sankar Nethralaya (SN) in Madras have tried unsuccessully to set up joint research projects with Indian geneticists and basic researchers. Given the urgency and the magnitude of the problem of retinosa pigmentosa in India, the worldwide prevalence of the disease, and the necessity for comparative studies, they sought out foreign collaborators, and the same is probably true of the other eye hospitals mentioned in the report.

The eye institute says that the funds it has received for the blood samples merely cover the reimbursement of the costs of clinical analysis, patient care and food and transportation, amounting to less than US\$20,000, and denies that it is to receive US $\$ 180,000$ for the future supply of human blood.

Finally, I should like to add that international collaboration between medical researchers, including collaboration that requires the exchange of genetic material, is a noble, uncommercial activity. It needs to be emphasized that the issues raised in your articles are qualitatively different from concern about patenting, licensing and intellectual property rights concerning medicinal plants, seed and other agricultural materials.

\section{Balasubramanian \\ (Director) \\ Centre for Cellular \\ and Molecuar Biology, \\ Hyderabad 500 007, India}

SIR - It is sad to read the criticism being levelled against the 'illegal' export of human DNA and blood samples from India for medical research on the grounds that it represents a plunder of India's genetic material.

Many important human genes for inherited diseases have been discovered in recent years, each involving several hundred person-years of research work with patients' samples collected from dozens of hospitals across the globe. For India to participate in such collaborative ventures does not represent pillage, but a creditable achievement.

Furthermore, research laboratories in the developed world are often criticized for neglecting problems relevant to developing countries. To complain at the same time that human biological samples are being plundered from the latter is therefore selfcontradictory, as it is obviously impossible to work on diseases such as giardiasis or leprosy without appropriate material from patients. 'Gene-hunting' research is no different, either conceptually or operationally, from that on infectious diseases.

There is a question of human rights. The genetic material referred to is associated with the right of individuals to decide whether to provide their informed consent to particular forms of treatment, including research into the disease from which they suffer. Any government regulations that prevent such individuals from making a free choice in such circumstances would appear to violate a fundamental right, and are therefore unconstitutional. The individuals in question approached the clinics voluntarily, seeking relief from their ailments; experience worldwide has shown that such individuals often express keen interest in cooperating with researchers attempting to trace the cause of their ailment. An incurable disease such as retinitis pigmentosa is devastating for its victims. Any research into its causes, even if it transcends national boundaries, should be praised rather than criticized.

If the current debate eventually codifies the way in which appropriate credit, both intellectual and financial, is allocated to Indian participants involved, through the identification of affected families, in any new discovery that emerges, it will have served its purpose. But if the debate merely results in the cause of diseases remaining undiscovered for decades to come, it will be a distressing outcome, not least for the patients concerned.

\section{J. Gowrishankar \\ Centre for Cellular \\ and Molecular Biology, \\ Hyderabad 500 007, India}

SIR - One of the current aims of the United Nations Educational, Scientific and Cultural Organisation (UNESCO) is to give developing countries an opportunity to participate in the human genome project. At the request of Indian colleagues at the third Unesco South-North Human Genome Conference, cosponsored by the International Centre for Genetic Engineering and Biotechnology, in New Delhi last December, an ad hoc committee drafted a statement.

This pointed out that scientists attending the meeting had acknowledged the need for the dissemination to the public of accurate and understandable information about the medical and scientific benefits that will emerge from increasing knowledge of the human and other genomes. The application of such knowledge has already made significant contributions to the fields of medical diagnosis, therapy and agriculture. At the same time, the appropriate use of the potential economic return from such biotechnological applications is of concern to both developed and developing countries.

The statement added that India's ethnic diversity and its large population is already contributing to knowledge about human genomic diversity. Indian scientists and their international collaborators support the goal that developing nations and individual ethnic groups should receive their appropriate share of the economic and commercial returns derived from medical investigations, including both clinical trials and genetic epidemiological studies, using biological material derived from their population groups.

\section{Santiago Grisolia}

(Chairman, UNESCO Scientific

Coordinating Committee for

the Human Genome Program)

Fundacion Valenciana de

Investigaciones Biomedicas,

Amadeo de Saboya 4,

46010 Valencia, Spain

\section{Public scepticism}

SIR - Christopher B. Johnson's statement (Nature 380, 18; 1996) that "it is not immediately obvious why the principle of healthy scepticism of scientific truths should be perceived as laudable within the scientific community but as unfortunate within the population at large" sounds somewhat surprising. The explanation is simple: nowhere on Earth at any time in human history has "the population at large" been educated to appreciate and practise scepticism about alleged "truths", those of a religious and ideological nature in particular. The fate (even now) of bravely "misbehaving" individuals is well known. So how can one possibly expect people "at large" to be enlightened enough to applaud "scepticism of scientific truths"?

Helmut Grünewald

Hauptstrasse 58 ,

D-95369 Untersteinach,

Germany

NATURE · VOL $380 \cdot 25$ APRIL 1996 